\title{
Reconsidering production coordination: A principal-agent theory-based analysis
}

\author{
Gong, D. ${ }^{a, b, c}$, Tang, M. ${ }^{b, c,{ }^{*}}$, Liu, S. ${ }^{b, c}$, Li,,${ }^{b, c}$ \\ ${ }^{a}$ School of Economics and Management, Tsinghua University, China \\ ${ }^{b}$ School of Economics and Management, Beijing Jiaotong University, China \\ 'International Center for Informatics Research, Beijing Jiaotong University, China
}

\section{A B S T R A C T}

Production coordination is a common phenomenon in supply chains. Unlike the existing literature, we examine the production coordination problem from the perspective of asymmetric information: how a manufacturer (leading firm) coordinates the relationships with its subsidiary firm(s) and, subsequently, how market returns influence the leading firm's expected utilities, agency cost and the subsidiary firm's expected incomes. We develop an incentive contract model with asymmetric information based on principal-agent theory. Comparative analysis and simulations are conducted to test the model. Results show that the leading firm's expected utilities and agency cost and the subsidiary firm's expected incomes are significantly affected by the subsidiary firm's capability, cost coefficient, absolute risk aversion factor and output variance (common factors); sharp differences among the leading firm's expected utilities and agency cost and the subsidiary firm's expected incomes were found due to different market returns. Thus, the proposed approach (incentive contract model) can help leading firms apply incentives to optimize production modes to obtain production coordination while considering common factors; market returns differences are included in the new model, in contrast to previous approaches.
\end{abstract}

\section{ARTICLE INFO}

Keywords:

Principal-agent theory

Production coordination

Market returns

Information asymmetry

Incentive

*Corresponding author:

mincong@bjtu.edu.cn

(Tang, M.)

Article history:

Received 17 November 2016

Revised 20 December 2016

Accepted 9 February 2017

\section{References}

[1] Lee, H.L. (2000). Creating value through supply chain integration, Supply Chain Management Review, 30-36.

[2] Matičević, G., Lovrić, T., Čičak, M. (2007), Using ERP system to improve internal supply chain coordination, Tehnički vjesnik - Techical Gazette, Vol. 14, No. 3-4, 11-21.

[3] Gong, D., Liu, S., Lu, X. (2015). Modelling the impacts of resource sharing on supply chain efficiency, International Journal of Simulation Modelling, Vol. 14, No. 4, 744-755, doi: 10.2507/IJSIMM14(4)CO20.

[4] Galić, M., Završki, I., Dolaček-Alduk, Z. (2016), Methodology and algorithm for asphalt supply chain optimization, Tehnički vjesnik - Techical Gazette, Vol. 23, No. 4, 1193-1199, doi: 10.17559/TV-20150623140015.

[5] Jiao, J.(R.), You, X., Kumar, A. (2006). An agent-based framework for collaborative negotiation in the global manufacturing supply chain network, Robotics and Computer-Integrated Manufacturing, Vol. 22, No. 3, 239-255, doi: 10.1016/i.reim.2005.04.003.

[6] Sahay, B.S. (2003). Supply chain collaboration: The key to value creation, Work Study, Vol. 52, No. 2, 76-83, doi: $10.1108 / 00438020310462872$.

[7] Nagarajan, M., Sošić, G. (2008). Game-theoretic analysis of cooperation among supply chain agents: Review and extensions, European Journal of Operational Research, Vol. 187, No. 3, 719-745, doi: 10.1016/j.ejor.2006.05.045.

[8] Brintrup, A. (2010). Behaviour adaptation in the multi-agent, multi-objective and multi-role supply chain, Computers in Industry, Vol. 61, No. 7, 636-645, doi: 10.1016/i.compind.2010.03.010.

[9] Akanle, O.M., Zhang, D.Z. (2008). Agent-based model for optimising supply-chain configurations, International Journal of Production Economics, Vol. 115, No. 2, 444-460, doi: 10.1016/i.ijpe.2008.02.019. 
[10] Yi, H.Y., Guo, P. (2015). Modelling risk coordination of supply chains with put option contracts and selective return policies, International Journal of Simulation Modelling, Vol. 14, No. 3, 551-562, doi: 10.2507/IJSIMM14 (3) C015.

[11] Saha, S., Goyal, S.K. (2015). Supply chain coordination contracts with inventory level and retail price dependent demand, International Journal of Production Economics, Vol. 161, 140-152, doi: 10.1016/j.ijpe.2014.12.025.

[12] Xu, L., Li, Y., Govindan, K., Xu, X. (2015). Consumer returns policies with endogenous deadline and supply chain coordination, European Journal of Operational Research, Vol. 242, No. 1, 88-99, doi: 10.1016/i.ejor.2014.09.049.

[13] Compte, O., Jehiel, P. (2008). Gathering information before signing a contract: A screening perspective, International Journal of Industrial Organization, Vol. 26, No. 1, 206-212, doi: 10.1016/j.ijindorg.2006.11.002.

[14] Cohen Kulp, S. (2002). The effect of information precision and information reliability in manufacturer-retailer relationships, The Accounting Review, Vol. 77, No. 3, 653-677, doi: 10.2308/accr.2002.77.3.653.

[15] Ho, C.-J., Slivkins, A., Wortman Vaughan, J. (2016). Adaptive contract design for crowdsourcing markets: Bandit algorithms for repeated principal-agent problems, Journal of Artificial Intelligence Research, Vol. 55, 317-359, doi:10.1613/jair.4940.

[16] Winkler, H., Kraus, S. (2011). Management of principal-agent problems in supply chains, International Journal of Business Research, Vol. 11, No. 2, 12-22.

[17] Keser, C., Willinger, M. (2007). Theories of behavior in principal-agent relationships with hidden action, European Economic Review, Vol. 51, No. 6, 1514-1533, doi: 10.1016/j.euroecorev.2006.10.007.

[18] Rubin, J., Sheremeta, R. (2015). Principal-agent settings with random shocks, Management Science, Vol. 62, No. 4, 985-999, doi: 10.1287/mnsc.2015.2177.

[19] Mukherji, A., Wright, P., Mukherji, J. (2007). Cohesiveness and goals in agency networks: Explaining conflict and cooperation, The Journal of Socio-Economics, Vol. 36, No. 6, 949-964, doi: 10.1016/j.socec.2007.01.024.

[20] Lal, R., Srinivasan, V. (1993). Compensation plans for single- and multi-product salesforces: An application of the Holmstrom-Milgrom model, Management Science, Vol. 39, No. 7, 777-793, doi: 10.1287/mnsc.39.7.777.

[21] Xu, W.Y., Zhang, Z.J., Gong, D.Q. (2014). Cooperative supply chain management under asymmetric information, Journal of Applied Research and Technology, Vol. 12, No. 2, 182-191 doi: 10.1016/S1665-6423(14)72334-X. 


\section{APEM}

\title{
Nov pristop za usklajevanje proizvodnje: Teoretska analiza stranka-posrednik
}

\author{
Gong, D. ${ }^{a, b, c}$, Tang, M. ${ }^{b, c,{ }^{*}}$, Liu, S. ${ }^{b, c}$, Li, Q. ${ }^{b, c}$ \\ ${ }^{a}$ School of Economics and Management, Tsinghua University, China \\ ${ }^{b}$ School of Economics and Management, Beijing Jiaotong University, China \\ 'International Center for Informatics Research, Beijing Jiaotong University, China
}

\begin{abstract}
POVZETEK
Usklajevanje proizvodnje je pomemben vidik v dobavnih verigah. V nasprotju $\mathrm{z}$ obstoječo literaturo obravnavamo usklajevanje proizvodnje $\mathrm{z}$ vidika asimetričnih informacij: kako proizvajalec (vodilno podjetje) usklajuje odnose s svojimi hčerinskimi podjetji (strankami) in posledično, kako tržni donosi vplivajo na pričakovano zadovoljstvo vodilnega podjetja, stroške posrednika in pričakovane dohodke hčerinskih podjetij. Razvit je model spodbujevalnih pogodb $\mathrm{z}$ asimetričnimi informacijami, ki temeljijo na teoriji strankaposrednik. Za testiranje modela so izvedene primerjalne študije in simulacije. Rezultati razkrijejo, da so pričakovano zadovoljstvo vodilnega podjetja, stroški posrednika in pričakovani dohodki hčerinskih podjetij močno odvisni od sposobnosti hčerinskega podjetja, stroškovnega koeficienta, absolutnega faktorja vpliva tveganja in izhodne variance (skupna dejavnika); nasprotja med pričakovanim zadovoljstvom vodilnega podjetja, stroški posrednika in pričakovanimi dohodki hčerinskih podjetij so posledica različnih tržnih donosov. Predlagani pristop (model spodbujevalnih pogodb) lahko pomaga vodilnim podjetjem uporabiti spodbude za optimizacijo proizvodnih modelov za izboljšanje uskladitve proizvodnje $\mathrm{z}$ ozirom na pomembne dejavnike. $\mathrm{V}$ pričujoči raziskavi so razlike $\mathrm{v}$ tržnih donosih vključene $\mathrm{v}$ nov model, kar pa $\mathrm{v}$ dosedanjih raziskavah ni bilo narejeno.
\end{abstract}

\section{PODATKI O ČLANKU}

Ključne besede:

Teorija stranka-posrednik

Koordinacija proizvodnje

Tržni donos

Informacijska asimetrija

Spodbuda

*Kontaktna oseba:

mincong@bjtu.edu.cn

(Tang, M.)

Zgodovina članka:

Prejet 17. novembra 2016

Popravljen 20. decembra 2016

Sprejet 9. februarja 2017 